\title{
A unifying approach to fatigue design in presence of defects and notches subject to uniaxial loading
}

\author{
Bruno Atzori ${ }^{1, a}$, Paolo Lazzarin ${ }^{2}$ and Giovanni Meneghetti ${ }^{1}$ \\ ${ }^{1}$ Department of Industrial Engineering, University of Padova, via Venezia, 1, 35131 Padova, Italy \\ ${ }^{2}$ Department of Management and Engineering, University of Padova, Str. S. Nicola, 1, 36100 Vicenza, \\ Italy
}

\begin{abstract}
In the recent past, Atzori and Lazzarin proposed a diagram able to include the geometrical effects on the fatigue limit of defects, short cracks, long cracks and U-shaped notches of whatever severity. The diagram shows that defect sensitivity and notch sensitivity can be considered as two sides of the same medal, thus creating a bridging between Linear Elastic Fracture Mechanics and Notch Mechanics. The fundamental material parameter, dependent on the load ratio, necessary to define the diagram is the El Haddad-Smith-Topper length parameter $\mathrm{a}_{0}$ defined by the plain material fatigue limit and the threshold value of the mode I stress intensity factor for long cracks. It is worth noting that $\mathrm{a}_{0}$ does not contain any geometry-related parameter. The diagram has been validated in the past against a number of experimental results and has been subsequently extended to sharp and blunt V-shaped notches, dependent on their absolute dimensions. After summarising the theory supporting the approach, some application examples relevant to both defect and notch sensitivity will be given.
\end{abstract}

\section{Introduction}

Traditionally, $\mathrm{K}_{\mathrm{t}}$-based approaches are used for assessing notched mechanical components against fatigue failure [1]. When the notch radius tends to zero, $\mathrm{K}_{\mathrm{t}}$-based approaches to fatigue limit analysis (even though corrected by the sensitivity index) are of limited applicability because stresses growth to infinity. It is well known that Fracture Mechanics concepts must be adopted to approach this problem [2]. Kitagawa and Takahashi first analysed experimentally the threshold conditions of a crack as a function of its length [3].

The threshold stress for a crack centred in an infinitely wide plate subject to mode I loading can be described by means the El Haddad-Smith-Topper equation [4]:

$$
\Delta \sigma_{\mathrm{g}, \mathrm{th}}=\frac{\Delta \mathrm{K}_{\mathrm{th}}}{\sqrt{\pi\left(\mathrm{a}+\mathrm{a}_{0}\right)}} \cdot
$$

In the recent past, Atzori and Lazzarin proposed a diagram for fatigue limit assessments valid for short/long cracks, crack-like notches and blunt notches with parallel flanks centred in an infinite plate

\footnotetext{
${ }^{a}$ Corresponding author: bruno. atzori@unipd.it
}

This is an Open Access article distributed under the terms of the Creative Commons Attribution License 4.0, which permits unrestricted use, distribution, and reproduction in any medium, provided the original work is properly cited. 


\section{MATEC Web of Conferences}

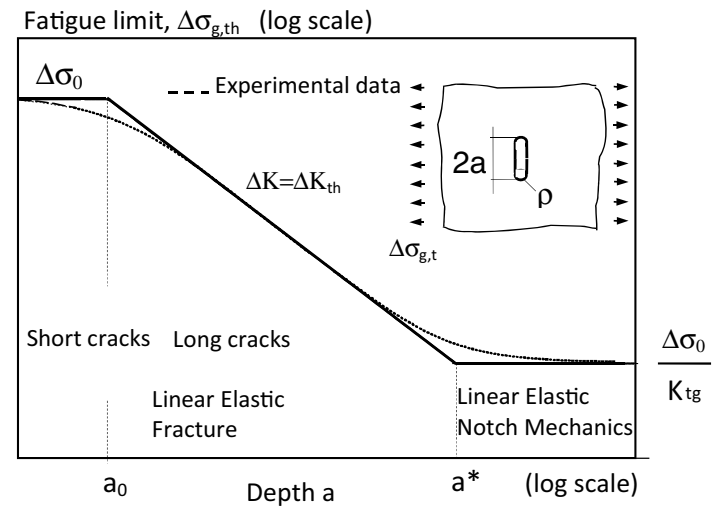

Figure 1. Fatigue limit estimation according to Atzori and Lazzarin's diagram for notches with constant a/ $\rho$ acuity and $\mathrm{a}^{*}=\left(\mathrm{K}_{\mathrm{t}}\right)^{2} \times \mathrm{a}_{0}$ (short and long cracks are included).

and subject to a remotely applied tensile stress, as shown in Fig. 1 [5]. The diagram was drawn by evaluating analytically the fatigue limit of the notch with respect to a variation of its absolute dimensions, being the stress concentration factor unchanged, i.e. by keeping the notch acuity $\zeta$, defined as the ratio between the notch depth "a" and the root radius $\rho$, unchanged. The fatigue limit is simply given by $\Delta \sigma_{0} / K_{\mathrm{tg}}\left(\Delta \sigma_{0}=\right.$ plain material fatigue limit; $\mathrm{K}_{\mathrm{tg}}=$ gross-section elastic stress concentration factor), if the absolute dimensions are sufficiently high. By reducing the notch dimensions the fatigue behaviour conforms to the $\Delta \mathrm{K}_{\mathrm{th}}$ line ( $\Delta \mathrm{K}_{\mathrm{th}}=$ threshold range of the stress intensity factor for long cracks), when the notch depth a becomes smaller than the characteristic value $\mathrm{a}^{*}$. Schematically, if the notch depth is between $\mathrm{a}_{0}$ and $\mathrm{a}^{*}$, then the fatigue behaviour is fully governed by the LEFM (so that the fatigue limit is equal to that of a crack having the same size), being $\mathrm{a}_{0}$ the El Haddad-Smith-Topper parameter [4], defined as:

$$
\mathrm{a}_{0}=\frac{1}{\pi}\left(\frac{\Delta \mathrm{K}_{\mathrm{th}}}{\Delta \sigma_{0}}\right)^{2}
$$

According to the schematic behaviour in Fig. 1, the notch sensitivity is full when a $>a^{*}$; on the other side, when a $<\mathrm{a}_{0}$ the defect sensitivity is null and $\Delta \sigma_{\mathrm{g}, \mathrm{th}}$ approaches the material fatigue limit.

An extension to account for the specimens' finite size was reported in [6]. Subsequently the diagram was validated against several experimental fatigue limits generated from blunt as well as sharp, cracklike notches [7]. The engineering tool reported in Fig. 1 was further extended in order to include notches of whatever opening angle $2 \alpha\left(2 \alpha=0^{\circ}\right.$ for a crack and U-shaped rounded notches) [8]. This task was accomplished by substituting the Stress Intensity Factor (SIF), $\mathrm{K}_{\mathrm{I}}$, with the Notch Stress Intensity Factor (NSIF), $K_{I}^{V}$, in the expression (1). $K_{I}^{V}$ is defined as [9]:

$$
K_{I}^{V}=\sqrt{2 \pi} \lim _{r \rightarrow 0}\left[\sigma_{\theta \theta}(\mathrm{r}, \theta=0) \mathrm{r}^{1-\lambda_{1}}\right]
$$

where $\sigma_{\theta \theta}$ is the opening stress component evaluated along the notch bisector ( $\theta=0$ direction), $\mathrm{r}$ and $\theta$ are according a polar coordinate system centred at the V-notch tip, and $\left(1-\lambda_{1}\right)$ is the degree of singularity of the stress field defined by Williams [10]. Then, Eq. (1) can be re-written for a general sharp V-shaped notch as:

$$
\Delta \sigma_{\mathrm{g}, \mathrm{th}}=\frac{\Delta \mathrm{K}_{\mathrm{I}, \mathrm{th}}^{\mathrm{V}}}{\sqrt{\pi}\left(\mathrm{a}_{\mathrm{eff}}+\mathrm{a}_{0}^{\mathrm{V}}\right)^{\gamma}}
$$




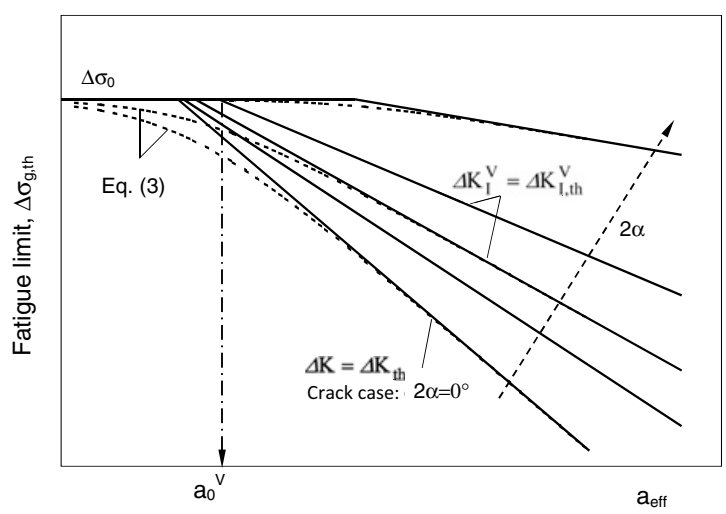

Figure 2. Fatigue limit of sharp V-shaped notches (from [8]).

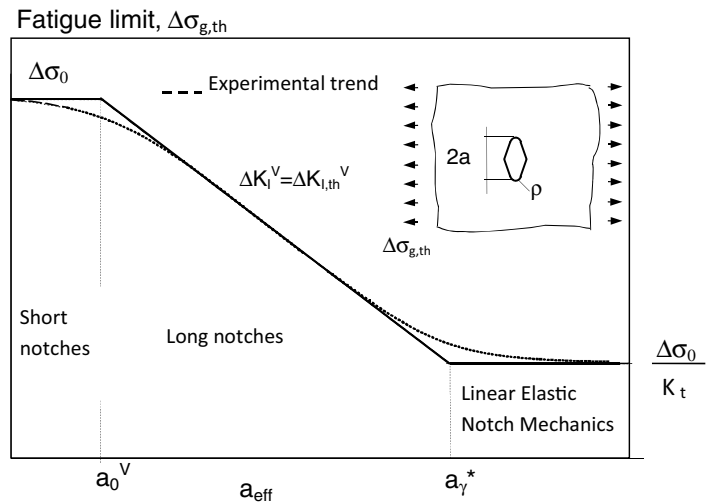

Figure 3. Fatigue limit of notches (cracks as well as U- and V-notches with any opening angle $2 \alpha$, size and notch root radius are included) [8].

where $\gamma=\left(1-\lambda_{1}\right)$ and $\mathrm{a}_{\mathrm{eff}}$ is defined on the basis of the following NSIF equality:

$$
\mathrm{a}_{\mathrm{eff}}=\left(\frac{\Delta \mathrm{K}_{\mathrm{I}}^{\mathrm{V}}}{\sqrt{\pi} \Delta \sigma_{\mathrm{g}}}\right)^{1 / \gamma} .
$$

Parameter $\mathrm{a}_{0}^{\mathrm{V}}$ is defined (similarly to the El-Haddad-Smith-Topper length parameter $\mathrm{a}_{0}$ ) by the limit condition that $\Delta \sigma_{\mathrm{g}, \mathrm{th}}$ approaches $\Delta \sigma_{0}$ when $\mathrm{a}_{\mathrm{eff}}$ tends to zero:

$$
\mathrm{a}_{0}^{\mathrm{V}}=\left(\frac{\Delta \mathrm{K}_{\mathrm{I}, \mathrm{th}}^{\mathrm{V}}}{\sqrt{\pi} \Delta \sigma_{0}}\right)^{1 / \gamma} .
$$

In Eqs. ((4), (6)) $\Delta \mathrm{K}_{\mathrm{I}, \mathrm{V}}^{\mathrm{V}}$ is a material parameter dependent on the applied mean stress, having the same meaning of the threshold value of the SIF for cracks. It can be determined from experimental tests conduced on sharp-V notched specimens. Figure 2 reports Eq. (4) valid for sharp notches evaluated for several notch opening angles, while Fig. 3 includes both sharp and blunt notches for a given notch opening angle. 


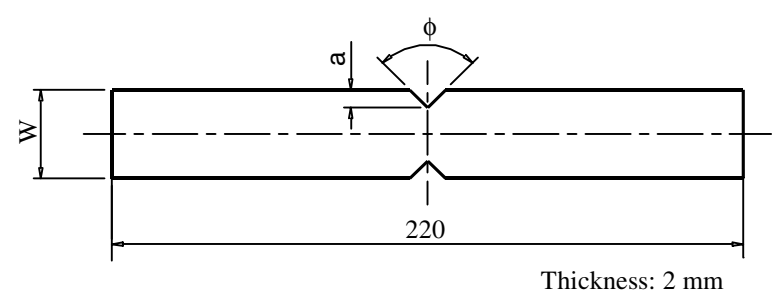

Figure 4. Geometry of the sharply notched specimens.

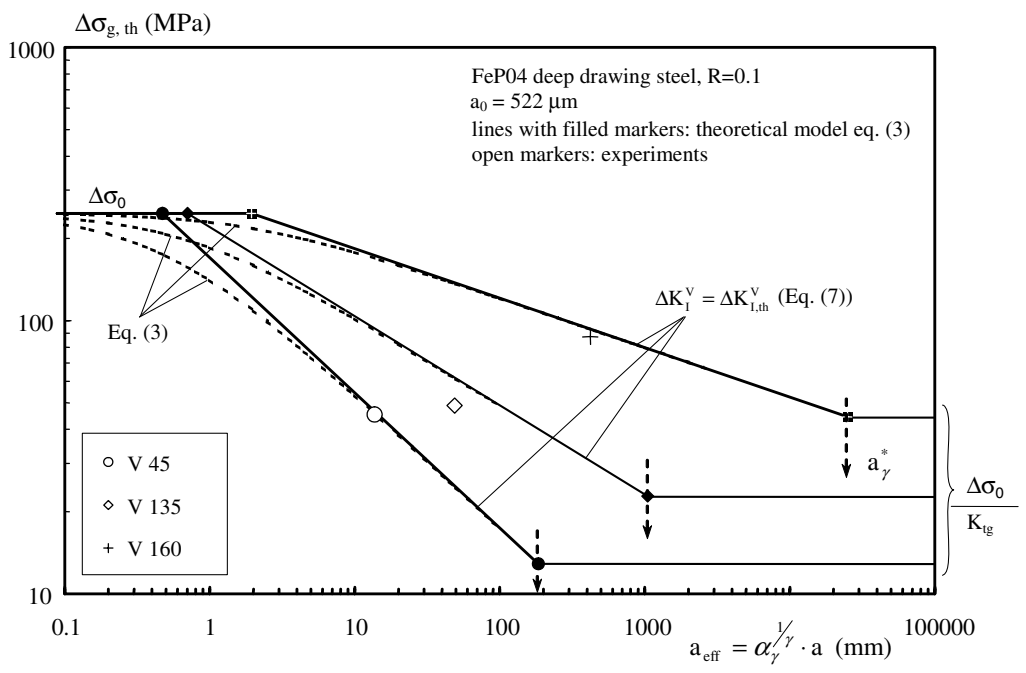

Figure 5. Comparison between fatigue model (Eq. (4)) and the experimental fatigue test results.

Moreover, it was shown that there exists a relation between the threshold values of the SIF and NSIF on the basis of proper local fatigue models [8]. As a results, the following expression was derived:

$$
\Delta \mathrm{K}_{\mathrm{I}, \mathrm{th}}^{\mathrm{V}}=\beta \cdot \Delta \sigma_{0}^{(1-2 \gamma)} \cdot \Delta \mathrm{K}_{\mathrm{th}}^{2 \gamma}
$$

where $\beta$ is a known parameter reported in [8], which depends on the notch opening angle $2 \alpha$. It should be noted that the threshold SIF and the material fatigue limit appearing in Eq. (7) are easier to find in the technical literature than the threshold NSIF of Eq. (3).

\section{Fatigue limit of specimens containing sharp V-shaped notches}

As a validation example, we consider the fatigue test results generated from 2-mm-thick FeP04 deepdrawing steel sheets (ultimate tensile strength $\sigma_{\mathrm{u}}=310 \mathrm{MPa}, 0.2 \%$ off-set yield stress $\sigma_{y}=185 \mathrm{MPa}$ ) reported in [11], to which the reader is referred for details on the finite element stress analyses performed. The specimen geometry is shown in Fig. 4: three series were tested, which were characterised by a notch opening angle $\phi$ equal to $45^{\circ}, 135^{\circ}$ and $160^{\circ}$, respectively. Figure 5 shows the fair agreement existing between theoretical estimations and experimental results. 


\section{Conclusions}

A fatigue model has been presented to estimate the fatigue limit of components weakened by short/long cracks as well as U- or V-shaped, sharp or blunt notches subject to mode I loading. The model requires two material parameters (namely the plain material fatigue limit and the threshold range of the stress intensity factor for long cracks) and two stress analyses (the elastic stress concentration factor and the notch stress intensity factor) to be applied.

\section{References}

[1] N.E. Frost, K.J. Marsh, L.P. Pook, Metal Fatigue (Oxford University Press, Oxford, 1974)

[2] R.A. Smith, K.J. Miller, Int J. Mech. Sci. 20, 201 (1978)

[3] H. Kitagawa, S. Takahashi, Procs. $2^{\text {nd }}$ Int. Conf. Mechanical Behaviour of Materials, 627 (1976)

[4] M.H. El Haddad, T.H. Topper, K.N. Smith, Eng. Fract. Mech. 11, 573 (1979)

[5] B. Atzori, P. Lazzarin, Int. J. Fract. 107, L3 (2001)

[6] B. Atzori, P. Lazzarin, Int. J. Fract. 118, 271 (2002)

[7] B. Atzori, P. Lazzarin, G. Meneghetti, Fatigue Fract. Eng. Mater. Struct. 26, 257 (2003)

[8] B. Atzori, P. Lazzarin, G. Meneghetti, Int. J. Fract. 133, 61 (2005)

[9] B. Gross, A. Mendelson, Int. J. Fract. Mech. 8, 267 (1972)

[10] M.L. Williams, J. Applied Mech. 19, 526 (1952)

[11] B. Atzori, P. Lazzarin, G. Meneghetti, Procs $9^{\text {th }}$ Int. Fatigue Congress "Fatigue 2006", (2006), On CD-rom 